\title{
INFLUENCE OF TRIMETAZIDINE METABOLIC THERAPY ON CONNECTIVE TISSUE METABOLISM IN EXPERIMENTAL DIFFUSE ISCHEMIC NECROTIC CARDIOSCLEROSIS IN RATS WITH DIFFERENT RATES OF HYPOXIA RESISTANCE
}

\author{
H. S. Saturska, Yu. I. Bondarenko, U. V. Saturska \\ I. HORBACHEVSKY TERNOPIL STATE MEDICAL UNIVERSITY, TERNOPIL, UKRAINE
}

Background. The change in metabolism of the connective tissue elements of heart is the central chain in pathogenesis of diffuse ischemic necrotic cardiosclerosis (DINC), which occurs after repeated epinephrine injury of myocardial tissues.

Objective. This study proves that trimetazidine (TM) metabolic therapy has a protective effect on the development of DINC in rats with different rates of hypoxia resistance.

Methods. Male white rats were divided into three groups due to the different rates of hypoxia resistance by means of the method of hypobaric hypoxia: rats with low, middle and high rates of hypoxia resistance. Each group was divided into equal subgroups: a control group, a DINC group (injections of epinephrine hydrotartrate $(0,5 \mathrm{mg} / \mathrm{kg}$ of body weight) and calcium gluconate (5 mg/kg of body weight) two times), a control group administrated with trimetazidine dihydrochloride (10 mg/kg of body weight), a DINC group treated with TM every day (10 mg/kg of body weight) for all period of observation. Concentration of protein-bound oxyproline in blood serum was evaluated on the $7^{\text {th }}, 14^{\text {th }}$ and $30^{\text {th }}$ days after the pathology simulation. Histological examination of Masson trichrome staining of myocardium was performed on the $30^{\text {th }}$ days after the pathology simulation.

Results. DINC increased the concentration of protein-bound oxyproline in blood serum on the $7^{\text {th }}, 14^{\text {th }}$ and $30^{\text {th }}$ days after the pathology simulation, and followed by metabolic imbalances in diffuse connective tissue elements, which are rich in collagens. DINC+TM increased the concentration of protein-bound oxyproline in blood serum less intensively.

Conclusions. The intensity of metabolic imbalances in diffuse connective tissue elements is the highest in the low resistant animals to hypoxia. Those results are confirmed by histological examination of the myocardium of rats with different resistance to hypoxia. Fibrotic regions in myocardium are rich in collagens. It has been revealed that the most pronounced therapeutic effect of TM is observed in animals with low resistance to hypoxia, slight - in animals with medium resistance to hypoxia, and the lowest - in animals with high resistance to hypoxia.

KEY WORDS: hypoxia, heart, diffuse cardiosclerosis, trimetazidine, oxyproline.

\section{Introduction}

The pathology of the cardiovascular system is the major medical and social problem, because it takes the main cause of morbidity and mortality [1-2]. The special attention is paid to the research on diagnostic markers of degradation and reparation of myocardial tissue [3-5], which would reflect the dynamic changes in myocardium and were predictors of diffuse cardiosclerosis [2-3]. The purpose of this investigation was to determine the changes in the

Address for correspondence: Hanna Saturska, Department of Social Medicine, Health Care Management, Economy and Medical Statistics, I. Horbachevsky Ternopil State Medical University, 1 Maidan Voli, Ternopil, Ukraine, 46001

Tel. +380352527233

E-mail: saturska@tdmu.edu.ua content of protein-bound oxyproline in blood as a diagnostic marker of metabolic activity of collagen at the experimental diffuse ischemic necrotic cardiosclerosis in rats with different rate of hypoxia resistance.

Recently, we demonstrated that the use of trimetazidine as an endogenous cardioprotection inducer in the development of diffuse ischemic necrotic cardiosclerosis is manifested by decrease in manifestations of oxidative and nitrooxidative stress, optimization of immune and cytokine response, stabilization of humoral immune responsiveness [6]. The research was carried out to study the effects of TM on the improvement of connective tissue elements metabolism, indicating inhibition of cardiosclerotic process. 


\section{Materials and Methods}

Animals and treatment

Experiments were done on 192 male white rats (190-250 g) of the vivarium of Ternopil State Medical University, Ukraine. All animals received care in compliance with the "Guide for Care and Use of Laboratory Animals" (National Institute of Health Publication № 85-23, revised 1985). The studies were carried out according to the National Institute of Health Guide for Care and Use of Laboratory Animals and were approved by the local animal protection committee.

The experimental animals were divided into three groups according to different rates of hypoxia resistance by means of the method of hypobaric hypoxia [6] [Berezovskyi, 1975; Markova, 1998]: rats with low, middle and high rates of hypoxia resistance. Each group was divided into equal subgroups: a control group, a diffuse ischemic necrotic cardiosclerosis group (injections of epinephrine hydrotartrate $(0,5 \mathrm{mg} / \mathrm{kg}$ body weight) and calcium gluconate $(5 \mathrm{mg} / \mathrm{kg}$ of body weight) two times), a control group administered with trimetazidine dihydrochloride (10 mg/kg of body weight) every day [6], diffuse ischemic necrotic cardiosclerosis group treated with trimetazidine dihydrochloride (10 $\mathrm{mg} / \mathrm{kg}$ of body weight) every day for all period of observation ( $n=8$ of each group).

Evaluation of protein-bound oxyproline in blood serum

Concentration of protein-bound oxyproline in blood serum was determined biochemically [7] on the $7^{\text {th }}, 14^{\text {th }}$ and $30^{\text {th }}$ days after the pathology simulating.

\section{Histopathology study}

The tissue from myocardium ventricles was taken on the $30^{\text {th }}$ day after pathology simulation, then put in $10 \%$ neutral-buffered formalin solution for 5 days, embedded in paraffin, and sectioned. Histological examination of Masson trichrome staining of myocardium was performed [8].

Statistical analysis

Statistical analysis was carried out by OriginPro Program. The results were presented as mean \pm standard deviation. Differences between experimental groups were analyzed with an unpaired two-tailed Student t-test [9]. Values were considered to be statistically significant at $p<0.05$.

\section{Results}

Before the DINC simulation the proteinbound oxyproline concentration in blood serum of rats with low hypoxia resistance was $17.8 \%$ $(p<0.05)$ higher than in blood serum of rats with middle hypoxia resistance (Table 1), oxyproline concentration in blood serum of high hypoxia resistant animals was $21.9 \%$ lower $(p<0.05)$ than in blood serum of rats with middle hypoxia resistance. After the DINC simulation proteinbound oxyproline concentration in blood serum of rats gradually increased at all groups.

Under the influence of trimetazidine metabolic therapy the changes in protein-bound oxyproline concentrations in blood serum of the animals with low hypoxia resistance were less pronounced (Table 2). Concentration of this metabolite collagen in 7 days after pathology simulation with TM was by $11.0 \%(p<0.05)$ (Figure 1) lower than in the group of untreated animals at this stage of observation. On the $14^{\text {th }}$ day after DINC simulation with TM, proteinbound oxyproline concentration in blood serum of the rats with low hypoxia resistance was by $25.3 \%$ lower $(p<0.001)$ than in the untreated animals, and on the $30^{\text {th }}$ day of observation it was by $33.9 \%(p<0.001)$ lower than in the

Table 1. Protein-bound oxyproline concentration in blood serum in cases of experimental diffuse ischemic necrotic cardiosclerosis (DINC) with innate hypoxia resistance in rats

\begin{tabular}{|c|c|c|c|c|}
\hline \multirow{2}{*}{$\begin{array}{l}\text { Hypoxia resistance } \\
\text { rate in animals }\end{array}$} & \multirow{2}{*}{$\begin{array}{c}\text { Control group } \\
(n=8)\end{array}$} & \multicolumn{3}{|c|}{ Stages of DINC observation } \\
\hline & & $\begin{array}{l}7 \text { days } \\
(n=8)\end{array}$ & $\begin{array}{c}14 \text { days } \\
(n=8)\end{array}$ & $\begin{array}{c}30 \text { days } \\
(n=8)\end{array}$ \\
\hline Low & $\begin{array}{c}49,55 \pm 0,59 \\
p<0,05\end{array}$ & $\begin{array}{c}57,45 \pm 1,78 \\
p<0,01 \\
p^{*}<0,01 \\
\end{array}$ & $\begin{array}{c}79,15 \pm 2,66 \\
p<0,01 \\
p^{*}<0,01\end{array}$ & $\begin{array}{c}104,84 \pm 3,42 \\
p<0,01 \\
p^{*}<0,01\end{array}$ \\
\hline Middle & $42,07 \pm 1,10$ & $\begin{array}{c}47,92 \pm 0,62 \\
\mathrm{p}^{*}<0,01\end{array}$ & $\begin{array}{c}58,24 \pm 1,00 \\
p^{*}<0,01\end{array}$ & $\begin{array}{c}73,38 \pm 3,30 \\
p^{*}<0,01\end{array}$ \\
\hline High & $\begin{array}{c}34,52 \pm 0,92 \\
p<0,05\end{array}$ & $\begin{array}{c}38,53 \pm 0,55 \\
p<0,01 \\
p^{*}<0,05\end{array}$ & $\begin{array}{c}42,65 \pm 1,19 \\
p<0,01 \\
p^{*}<0,01\end{array}$ & $\begin{array}{c}56,43 \pm 2,84 \\
p<0,01 \\
p^{*}<0,01\end{array}$ \\
\hline
\end{tabular}

Notes: $\mathrm{p}<0.05$ - significantly different from middle hypoxia resistant animals at all stages of observation; * $\mathrm{p}<0.05$ significantly different from the control group at all stages of observation. 
Table 2. Influence of trimetazidine on protein-bound oxyproline concentration in blood serum in cases of experimental diffuse ischemic necrotic cardiosclerosis (DINC) with innate hypoxia resistance in rats

\begin{tabular}{|c|c|c|c|c|}
\hline \multirow[b]{2}{*}{$\begin{array}{l}\text { Hypoxia resistance } \\
\text { rate in animals }\end{array}$} & \multirow{2}{*}{$\begin{array}{l}\text { Control TM group } \\
\qquad(\mathrm{n}=8)\end{array}$} & \multicolumn{3}{|c|}{ Stages of DINC+TM observation } \\
\hline & & $\begin{array}{l}7 \text { days } \\
(\mathrm{n}=8)\end{array}$ & $\begin{array}{c}14 \text { days } \\
(\mathrm{n}=8)\end{array}$ & $\begin{array}{c}30 \text { days } \\
(n=8)\end{array}$ \\
\hline Low & $45,58 \pm 1,51$ & $\begin{array}{c}51,15 \pm 1,36 \\
p^{*}<0,05 \\
p<0,001\end{array}$ & $\begin{array}{c}59,09 \pm 1,85 \\
p^{*}<0,001 \\
p<0,001\end{array}$ & $\begin{array}{c}69,32 \pm 1,86 \\
p^{*}<0,001 \\
p<0,001\end{array}$ \\
\hline Middle & $40,58 \pm 1,83$ & $43,97 \pm 1,34$ & $\begin{array}{c}40,58 \pm 1,83 \\
p^{*}<0,05\end{array}$ & $\begin{array}{c}52,72 \pm 3,15 \\
\mathrm{p}^{*}<0,05\end{array}$ \\
\hline High & $\begin{array}{c}34,90 \pm 0,96 \\
p<0,05\end{array}$ & $\begin{array}{c}36,33 \pm 0,91 \\
p<0,001\end{array}$ & $\begin{array}{c}37,72 \pm 1,52 \\
p<0,001\end{array}$ & $\begin{array}{c}34,90 \pm 0,96 \\
p^{*}<0,05 \\
p<0,01\end{array}$ \\
\hline
\end{tabular}

Notes: $p<0.05$ - significantly different from the middle hypoxia resistant of animals at all stages of observation; ${ }^{*} p<0.05$ - significantly different from the control group at all stages of observation.

untreated animals with low hypoxia resistance at the similar stage of cardiosclerotic process development without any correction.

In blood serum of the rats with middle hypoxia resistance, protein-bound oxyproline concentration on the $7^{\text {th }}$ day after DINC simulation and trimetazidine correction was by $8.3 \%$ $(p<0.05)$ (Fig. 1) lower than in the group of untreated animals at this stage of observation. At the next stage of observation, on the $14^{\text {th }}$ day of DINC simulation, protein-bound oxyproline concentration in blood serum of these animals was by $18.6 \%$ lower $(p<0.001)$ than in the untreated ones, and on the $30^{\text {th }}$ day of DINC observation - by $28.2 \%(p<0.001)$ lower than in the untreated rats.

There was no significantly difference between the treated and untreated animals with high hypoxia resistance on the $7^{\text {th }}$ day of DINC observation. On the $14^{\text {th }}$ day after the pathology simulation, protein-bound oxyproline concentration was lower by $11.6 \%(p<0.05)$ than in the group of untreated animals at this stage of observation; and on the $30^{\text {th }}$ day of DINC observation and correction with metabolic therapy, concentration of protein-bound oxyproline in blood serum was $28.4 \%(p<0.001)$ lower than in the untreated animals with high hypoxia resistance without any correction.

Histological examination of the myocardium on the $30^{\text {th }}$ day of DINC observation showed that at heart micropreparations of the healthy animals with different rates of hypoxia resistance, connective tissue was observed slightly in the form of thin collagen fibers (Figure 2), but in heart micropreparations of the animals with DINC (Figure 3) focal cardiosclerosis, perivascular sclerosis hyperelasticity of vessels

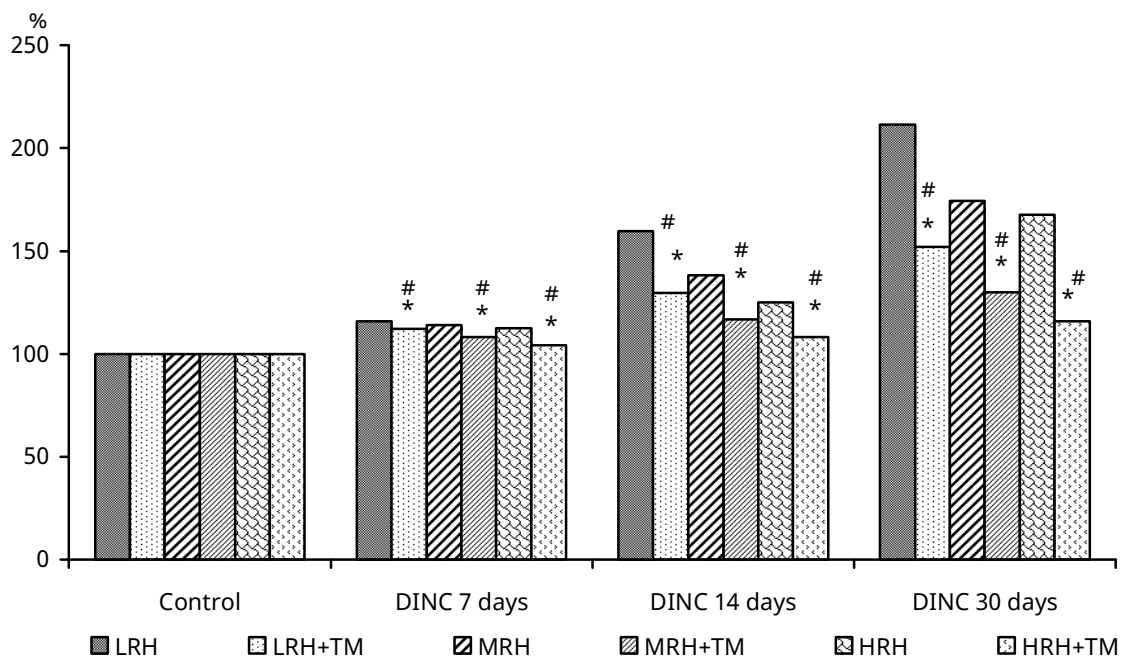

Fig. 1. Influence of trimetazidine on protein-bound oxyproline concentration in blood serum in cases of experimental diffuse ischemic necrotic cardiosclerosis (DINC) with innate hypoxia resistance in rats.

Notes: the indices of the control groups were presented in $100 \%$; * - significantly different from the control group at all stages of observation, $p<0.05$; \#- significantly different from the untreated rats at all stages of observation, $p<0.05$. 


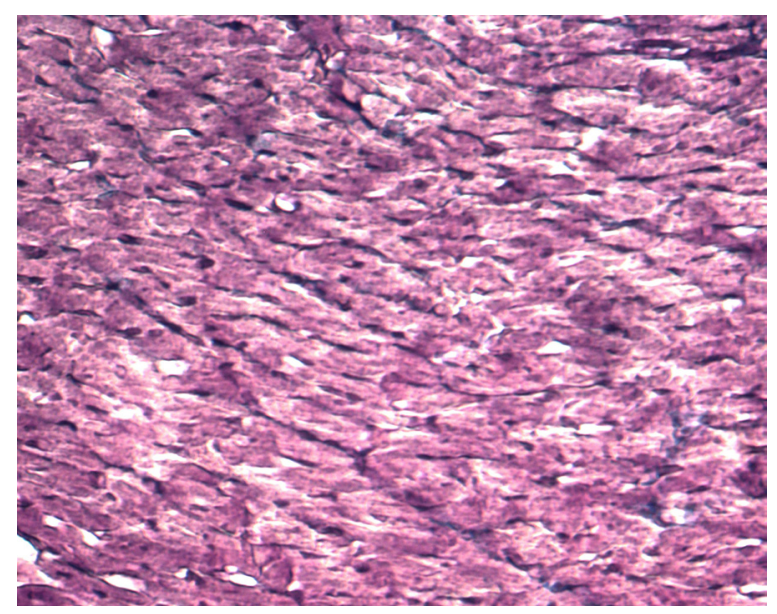

Fig. 2. Myocardium of the control rat. Masson trichrome staining of myocardium. $\times 400$.

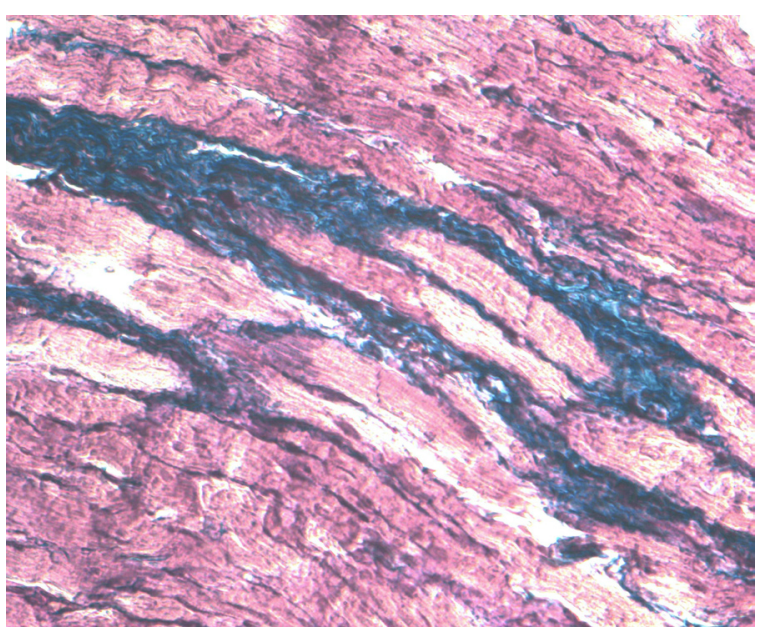

Fig. 3. Myocardium of the low hypoxia resistant rat with DINC. Fibrotic regions in myocardium are rich in collagens and therefore appear in blue upon Masson trichrome staining. In addition, centralized nuclei as well as shape and size distribution of myofibers were detected that was the evidence of pronounced cardiomyocytes hypertrophy. 30-day DINC. Masson trichrome staining of myocardium. $\mathrm{x} 400$.

inner membrane, cardiomyocyte hypertrophy, diffuse proliferation of connective tissue were presented. Fibrotic regions in myocardium are rich in collagens and therefore appear in blue upon Masson trichrome staining. In addition, centralized nuclei as well as shape and size distribution of myofibers were detected that was the evidence of pronounced cardiomyocytes hypertrophy.

All the above-mentioned symptoms are the highest in the low hypoxia resistant animals, indicating the intense development of diffuse cardiosclerosis in animals with low hypoxia resistance and confirm the results obtained during evaluation of the concentration of protein-bound oxyproline serum of rats with different rates of hypoxia resistance.

\section{Discussion}

Evaluation of protein-bound oxyproline concentrations in blood serum in DINC simulation with and without trimetazidine correction proved that increased collagen production and products of its metabolism [4-5] can be used as a biological marker of the intensity of collagen synthesis in tissue infarction. So we can make the following conclusion: the intensity of metabolic imbalance of connective elements in cases of diffuse ischemic necrotic cardiosclerosis and trimetazidine correction depends on hypoxia resistance of animals. In the low hypoxia resistance animals, maximum effect of trimetazidine correction was manifested; however, more pronounced changes in oxyproline concentration were in DINC simulation without any correction. This effect was not enough for denoting differences between animals with different rates of hypoxia resistance. This matter is characteristic feature of animals with middle hypoxia resistance, but the changes were less pronounced. Animals with high hypoxia resistance were characterized by lower oxyproline concentration, which changed after DINC simulation, so the effect was manifested less, but in general, they are characterized by minimal metabolic disorders of connective tissue elements in the development of DINC and correction with trimetazidine [10-16]. The activity of connective tissue metabolism was studied in experimental diffuse ischemic necrotic cardiosclerosis with different rates hypoxia resistance of a body. The investigations were based on the changes in concentration of protein-bound oxyproline in blood serum that proved adequate metabolic changes in collagen [4-5].

\section{Conclusions}

The development of the experimental diffuse ischemic necrotic cardiosclerosis at all stages of observation was accompanied by metabolic imbalance in connective tissue of heart, and was proved by the increase in oxyproline level in blood serum of animals with different rates of hypoxia resistance. The intensity of metabolic imbalances in diffuse connective tissue elements was the highest in low hypoxia resistant animals. Those results were confirmed by histological examination of myocardium of rats with different rates of hypoxia resistance. Fibrotic regions in myocardium are rich in collagens. It has been revealed that the most pronounced therapeutic effect of TM is observed in animals with low hypoxia resistance, 
slightly less - in animals with medium hypoxia resistance, and the lowest - in animals with high hypoxia resistance. This matter was evidenced at all stages of observation, but it was the most pronounced in the early period of cardiosclerotic process, indicating the feasibility of early use of metabolic therapy. It explains the absence of cardioprotective effect of trimetazidine in the later stages of cardiosclerosis, when the myocardial fibrosis is already formed.

\section{References}

1. Lopez AD, Mathers CD. Measuring the global burden of disease and epidemiological transitions: 2002-2030. Ann Trop Med Parasitol. 2006; 100(5-6): 481-499.

2. Salemi VM, Leite JJ, Picard MH et al. Echocardiographic predictors of functional capacity in endomyocardial fibrosis patients. Eur J Echocardiogr 2009; 10(3): 400-405.

3. Iglezias SD, Benvenuti LA, Calabrese F. et al. Endomyocardial fibrosis: pathological and molecular findings of surgically resected ventricular endomyocardium. Virchows Arch 2008; 453(3); 233-241.

4. Ito A, Yamagiwa H, Sasaki RJ. Effects of aging on hydroxyproline in human heart muscle. Am Geriatr Soc. 1980; 28(9): 398-404.

5. Hoerstrup SP, Zünd G, Ye Q, et al. Tissue engineering of a bioprosthetic heart valve: stimulation of extracellular matrix assessed byhydroxyproline assay. ASAIO J. 1999; 45(5): 397-402.

6. Saturska HS. Peculiarities of cardioprotective effect of trimetazidine at experimental cardiosclerosis in rats with different sensitivity to hypoxia. Vestnik of Vitebsk State Medical University 2015; 14(1): 34-40. (in Russian).

7. Sharaev PN. Method for determination of free and bound hydroxyproline in serum. Lab business 1981; 5: 283-285. (in Russian).

8. Merkulov GA. Course of histological techniques. L . : Medicine, 1969; 422 p. (in Russian).

9. Orlov AI. Mathematics cases: probability and statistics - the basic facts: a tutorial. M. : M-Press, 2004; 100 p. (in Russian).
10. Detry JM, Sellier P, Pennaforte $S$, et al. Trimetazidine: a new concept in the treatment of angina: comparison with propranolol in patients with stable angina. Trimetazidine European Multicenter Study Group. Br J Clin Pharmacol 1994; 37: 279-288.

11. Gupta R, Sawhney JP, Narain VS. Treatment of stable angina pectoris with trimetazidine modified release in Indian primary-care practice. Am J Cardiovasc Drugs. 2005; 5(5): 325-329.

12. Marzilli M, Klein WW. Efficacy and tolerability of trimetazidine in stable angina: a metaanalysis of randomized, double-blind, controlled trials. Coron Artery Dis 2003; 14: 171-179.

13. Sellier P, Broustet JP. Assessment of antiischemic and antianginal effect at trough plasma concentration and safety of trimetazidine MR $35 \mathrm{mg}$ in patients with stable angina pectoris: a multicenter, double-blind, placebo-controlled study. Am J Cardiovasc Drugs 2003; 3: 361-369.

14. Szwed H, Sadowski Z, Pachocki R, et al. Antiischaemic efficacy and tolerability of trimetazidine in elderly patients with angina. Clin Drug Invest 2000; 19: 1-8.

15. Szwed H, Sadowski Z, Pachocki R, et al. Combination treatment in stable effort angina using trimetazidine and metoprolol: results of a randomized, double-blind, multicentre study (TRIMPOL II). TRIMetazidine in POLand. Eur Heart J 2001; 22: 2267-2274.

16. Szwed H, Sadowski Z, Pachocki R, et al. The antiischemic effects and tolerability of trimetazidine in coronary diabetic patients: a substudy from TRIMPOL 1. Cardiovasc Drugs Ther 1999; 13: 217-222.

Received: 2016-03-04 